\title{
A cavity ring down/cavity enhanced absorption device for measurement of ambient $\mathrm{NO}_{3}$ and $\mathrm{N}_{2} \mathrm{O}_{5}$
}

\author{
G. Schuster ${ }^{1}$, I. Labazan ${ }^{1, *}$, and J. N. Crowley ${ }^{1}$ \\ ${ }^{1}$ Max-Planck-Institut für Chemie, Mainz, Germany \\ *now at: NXP Semiconductors, Nijmegen, The Netherlands
}

Received: 12 August 2008 - Published in Atmos. Meas. Tech. Discuss.: 9 September 2008

Revised: 8 December 2008 - Accepted: 8 December 2008 - Published: 7 January 2009

\begin{abstract}
An inexpensive, compact instrument for the sensitive measurement of $\mathrm{NO}_{3}$ and $\mathrm{N}_{2} \mathrm{O}_{5}$ in ambient air at high time resolution is described. Light from a red-emitting laser diode $(\approx 662 \mathrm{~nm})$ is coupled off-axis into an optical resonator defined by two highly reflective mirrors to achieve effective absorption paths exceeding $20 \mathrm{~km}$. Light leaking from the cavity is detected either as single ring-down events (time constant of $\approx 100 \mu \mathrm{s}$ ) following rapid switching of the laser intensity at $200 \mathrm{~Hz}$ (Cavity Ring Down mode), or as an integrated intensity (Cavity Enhanced Absorption mode). The operational conditions, detection limits ( 2 pptv in $5 \mathrm{~s}$ ) and total uncertainty $\left(<15 \%\right.$ for $\left.\mathrm{NO}_{3}>10 \mathrm{pptv}\right)$ for the prototype device for $\mathrm{NO}_{3}$ and $\mathrm{N}_{2} \mathrm{O}_{5}$ detection/monitoring are assessed and the first measurements in ambient air and from an environmental chamber are described.
\end{abstract}

\section{Introduction}

$\mathrm{NO}_{3}$ and $\mathrm{N}_{2} \mathrm{O}_{5}$ are important atmospheric trace gases (Wayne et al., 1991) which have a significant impact on the night-time oxidation of some organic compounds (e.g. aldehydes and dimethylsulphide), the partitioning of nitrogen oxides between the $\mathrm{NO}_{\mathrm{x}}\left(\mathrm{NO}+\mathrm{NO}_{2}\right)$ and $\mathrm{NO}_{\mathrm{y}}$ families (where $\mathrm{NO}_{\mathrm{y}}$ is the sum of all nitrogen oxides and includes long lived reservoir species such as $\mathrm{HNO}_{3}$ ) and also, via heterogeneous reactions, the partitioning of $\mathrm{NO}_{\mathrm{y}}$ between the gas and particulate phases. $\mathrm{NO}_{3}$ is formed predominantly in the reaction of $\mathrm{NO}_{2}$ with ozone (R1) and is converted to $\mathrm{N}_{2} \mathrm{O}_{5}$ via further reaction with $\mathrm{NO}_{2}(\mathrm{R} 2 \mathrm{a})$. Due to the thermal decomposition of $\mathrm{N}_{2} \mathrm{O}_{5}$, the relative concentrations of $\mathrm{NO}_{3}$ and $\mathrm{N}_{2} \mathrm{O}_{5}$ are closely linked (Brown et al., 2003) and are a strong function

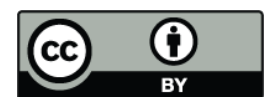

Correspondence to: J. N. Crowley (crowley@mpch-mainz.mpg.de) of temperature and $\left[\mathrm{NO}_{2}\right] . \mathrm{NO}_{3}$ absorbs red light efficiently (see Sect. 2.1) and is rapidly photolysed with a lifetime of only a few seconds during daytime, so that $\mathrm{NO}_{3}$ and (due to the equilibrium - R2a, b) $\mathrm{N}_{2} \mathrm{O}_{5}$ concentrations are very low. At night, $\mathrm{NO}_{3}$ can react with $\mathrm{NO}(\mathrm{R} 4)$ or with gas-phase organic species, RH (R5).

$\mathrm{NO}_{2}+\mathrm{O}_{3} \rightarrow \mathrm{NO}_{3}+\mathrm{O}_{2}$

$\mathrm{NO}_{2}+\mathrm{NO}_{3}+\mathrm{M} \rightarrow \mathrm{N}_{2} \mathrm{O}_{5}+\mathrm{M}$

$\mathrm{N}_{2} \mathrm{O}_{5}+\mathrm{M} \rightarrow \mathrm{NO}_{2}+\mathrm{NO}_{3}+\mathrm{M}$

$\mathrm{N}_{2} \mathrm{O}_{5}+$ aerosol $\rightarrow \mathrm{HNO}_{3}(p)$

$\mathrm{NO}_{3}+\mathrm{NO} \rightarrow 2 \mathrm{NO}_{2}$

$\mathrm{NO}_{3}+\mathrm{RH} \rightarrow$ products

$\mathrm{NO}_{3}$ has been measured in the atmosphere on several occasions: by differential optical absorption spectroscopy (DOAS), dating back several decades (see e.g. Platt et al., 1981), matrix isolation ESR (Geyer et al., 1999) and more recently, by laser cavity absorption techniques (e.g. King et al., 2000; Ball et al., 2001; Brown et al., 2002; Venables et al., 2006; Meinen et al., 2008; Nakayama et al., 2008) and laser induced fluorescence (e.g. Matsumoto et al., 2005; Wood et al., 2005).

$\mathrm{N}_{2} \mathrm{O}_{5}$ measurements are less common, though techniques using thermal conversion to $\mathrm{NO}_{3}$ which can be detected using optical (Brown et al., 2001; Simpson, 2003) and massspectrometer based methods (Slusher et al., 2004) have been described. Many of the available instruments include expensive, sensitive and bulky components (e.g. pulsed lasers, spectrographs, vacuum pumps) and are not always suitable for research platforms with space/weight constraints.

Published by Copernicus Publications on behalf of the European Geosciences Union. 

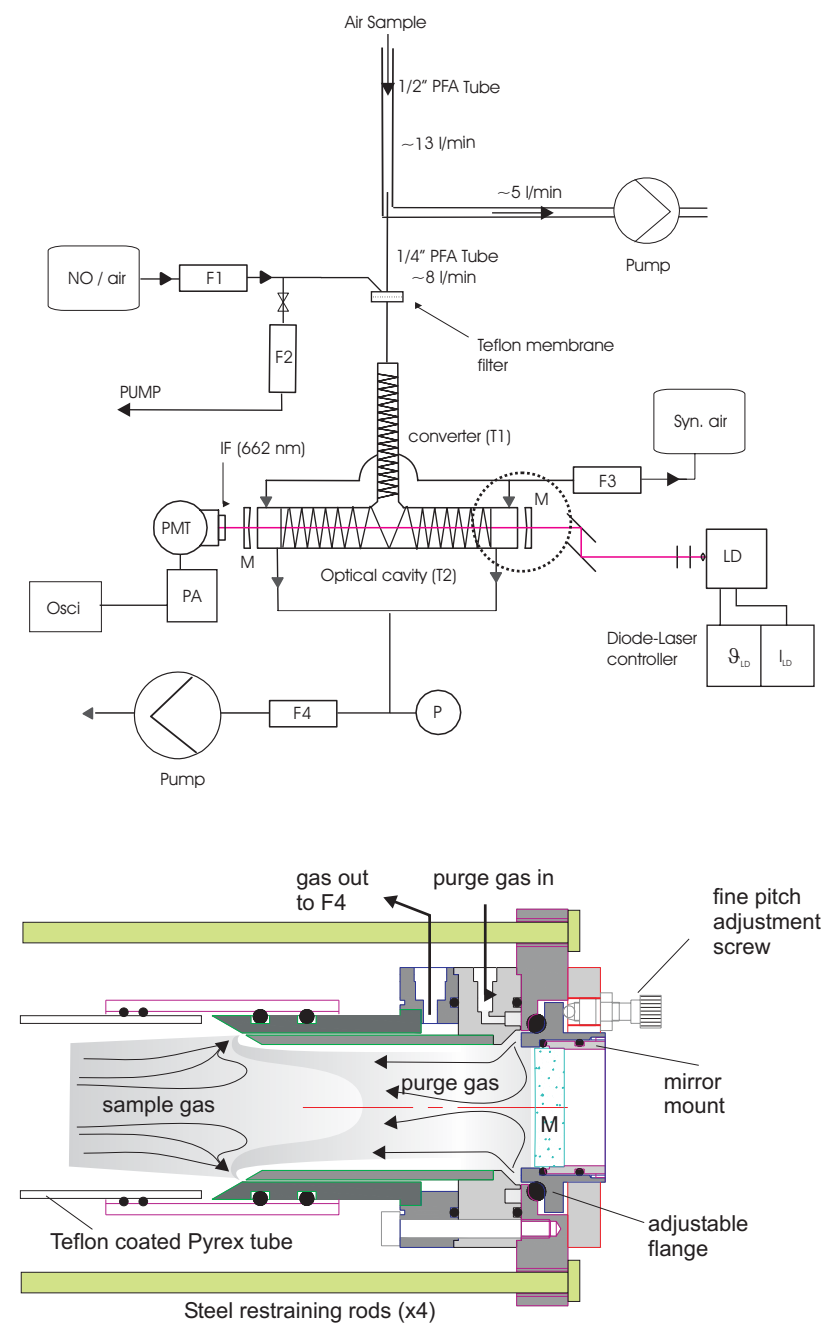

Fig. 1. Schematic/technical diagram of the instrument. F1-4: flow controllers $(10,10,1000$, and $10000 \mathrm{sccm}$, respectively), P: pressure gauge, M: $662 \mathrm{~nm}$ coated dielectric cavity mirrors, LD: laser diode, IF: interference filter centred at $662 \mathrm{~nm}$, Syn.air: bottled synthetic air for mirror purging, PMT: photomultiplier, Osci: digital oscilloscope for signal acquisition, PA: signal pre-amplifier, NO/air: bottled mixture of $100 \mathrm{ppmv} \mathrm{NO}$ in air for $\mathrm{NO}_{3}$ titration. The lower section of the figure gives a detailed view of the purge gas in- and outlets and the mirror mounts as enclosed in the dotted circle of the upper section.

Depending on air mass, $\mathrm{NO}_{3}$ concentrations may exceed 100 pptv, and $\mathrm{N}_{2} \mathrm{O}_{5}$ may exceed 1 ppbv. Frequently however, low production rates of $\mathrm{NO}_{3}$ (due e.g. to low $\left[\mathrm{NO}_{2}\right]$ and large loss rates of $\mathrm{NO}_{3}$ (due e.g. to gas phase reactions with organic species) or $\mathrm{N}_{2} \mathrm{O}_{5}$ (due to heterogeneous processing) result in lifetimes of the order of just a few minutes and levels of less than $10 \mathrm{pptv}$. Ideally, an instrument for measurement of atmospheric $\mathrm{NO}_{3}$ or $\mathrm{N}_{2} \mathrm{O}_{5}$ should be able to detect pptv levels of these trace gases on timescales of a few seconds in a well defined air-mass (point measurement). In addition, it should be lightweight, have a small footprint and low power consumption and, to facilitate widespread usage, should be made from relatively inexpensive, robust components. In its present state, our instrument is characterised by a total weight of $<40 \mathrm{~kg}$, approximate dimensions (excluding 2 small diaphragm pumps) of $90 \times 40 \times 40 \mathrm{~cm}(90 \times 40 \mathrm{~cm}$ footprint), power consumption of $<500 \mathrm{~W}$ and a total cost of close to $20 \mathrm{k}$ Euro.

The instrument we describe is an optical-cavity/laser absorption device. It is operated either in "cavity ringdown" (CRD) mode or "cavity enhanced absorption" mode (CEAS), which is closely related to "integrated cavity output spectroscopy" (ICOS). The basic principles of CRD and CEAS are described in recent, comprehensive review articles (Berden et al., 2000; Brown, 2003; Mazurenka et al., 2005). Here, we present a detailed description of the prototype device, results of laboratory characterisation, first measurement of $\mathrm{N}_{2} \mathrm{O}_{5}\left(+\mathrm{NO}_{3}\right)$ mixing ratios outside the Max Planck Institute building in Mainz and some results from the first deployment in a multi-instrument $\mathrm{NO}_{3} / \mathrm{N}_{2} \mathrm{O}_{5}$ intercomparison campaign. The inter-comparison was carried out at the SAPHIR environmental chamber (Rohrer et al., 2005) in Jülich, Germany in the summer of 2007 and the results will be presented in detail in forthcoming publications (Apodaca et al., 2008; Dorn et al., 2008).

\section{Experimental set up}

The instrument makes use of the well characterised, strong absorption band of $\mathrm{NO}_{3}$ between circa 610 and $665 \mathrm{~nm}$. Recent developments in laser optics, including the increasing availability of powerful, cheap, red emitting diode lasers and mirrors with extremely high reflectivity at appropriate wavelengths can be combined with the large absorption cross section of $\mathrm{NO}_{3}$ close to $660 \mathrm{~nm}$ to make cavity based detection methods a powerful tool for ambient $\mathrm{NO}_{3} / \mathrm{N}_{2} \mathrm{O}_{5}$ measurements.

The central component of our instrument is an optical cavity (resonator length $\approx 70 \mathrm{~cm}$ ) flushed with ambient air which can be operated either in cavity ring down (CRD) or cavity enhanced absorption (CEAS) mode. $\mathrm{NO}_{3}$, which possesses a distinct and intensive absorption feature at $\approx 662 \mathrm{~nm}$ is measured directly, whereas $\mathrm{N}_{2} \mathrm{O}_{5}\left(+\mathrm{NO}_{3}\right)$ is detected by heating part of the inlet and cavity to $95^{\circ} \mathrm{C}$ to dissociate it to $\mathrm{NO}_{3}$ (R2b). Using a value of $k_{2 b}=32 \mathrm{~s}^{-1}$ at this temperature and 1 atmosphere pressure (Sander et al., 2006), the lifetime of $\mathrm{N}_{2} \mathrm{O}_{5}$ w.r.t. dissociation to $\mathrm{NO}_{3}$ is less than $0.1 \mathrm{~s}$. By comparison, the lifetime at room temperature is $\approx 100 \mathrm{~s}$. Assuming no loss of $\mathrm{NO}_{3}$ via thermal dissociation, operation at $95^{\circ} \mathrm{C}$ means that the sum of $\mathrm{NO}_{3}$ and $\mathrm{N}_{2} \mathrm{O}_{5}$ concentrations is measured.

A schematic diagram illustrating the various optical, gasflow and electronic components is given in Fig. 1. In this paper the instrument is described for the first time. 


\subsection{Optical configuration}

The high finesse optical cavity consists of two, 1 inch diameter dielectric mirrors (radius of curvature $=1 \mathrm{~m}$, reflectivity $\approx 99998$, Los Gatos Research) located $\approx 70 \mathrm{~cm}$ apart in home built mounts (see inset to Fig. 1). The laser is coupled off-axis into the cavity to spatially separate the multiple reflections within the cavity and increase the number of passes before the re-entrant condition is fulfilled (i.e. when the beam retraces its original path). Compared to on-axis alignment, this reduces optical feedback and cavity intensity fluctuations, reduces the need for fine mechanical stability of the cavity, and increases the density of the cavity mode spectrum and free spectral range (Paul et al., 2001; Kasyutich et al., 2002; Bakhirkin et al., 2004; Ayers et al., 2005). Adjustment of the cavity is achieved by monitoring the cavity output for maximum ring down time, but also avoiding spurious, high-intensity cavity emissions due to incomplete suppression of cavity resonances (mode co-incidence between laser and unstabilised cavity). The cavity gain under such conditions is similar to that achieved when the laser is coupled to a single cavity mode, but the transmitted power level is drastically reduced (Paul et al., 2001). The laser current is modulated to slightly broaden the laser spectral bandwidth ensuring that the re-entrance length was longer than the laser coherence length. In CEAS mode, current modulation of the laser improves the signal/noise ratio $(\mathrm{S} / \mathrm{N})$ of the cavity emission by $\approx$ an order of magnitude but, as the wavelength jitter was small, does not reduce the effective absorption cross section. A similar improvement in $\mathrm{S} / \mathrm{N}$ was observed in an earlier version of the instrument in which the cavity length was dithered at $50 \mathrm{~Hz}$ by use of a piezo-electric transducer attached to one mirror mount (e.g. Kasyutich et al., 2002). The combination of both laser wavelength jitter and cavity dither did not improve the S/N compared to the use of either. The cavity material is Pyrex glass (ID $15 \mathrm{~mm}$ ), coated with a thin film of Teflon (DuPont FEP 121a). The laser used is a current modulated, $120 \mathrm{~mW}, \mathrm{CW}$ laser diode emitting close to $662 \mathrm{~nm}$ (Mitsubishi ML101 J27) with current and temperature control $\left(34.70^{\circ} \mathrm{C}\right)$ using a ThorLabs diode laser controller ITC 502.

Operation in both CEAS and CRD modes is possible with simultaneous measurement of integrated light intensity or ring down decay constants, respectively. In CRD mode, laser modulation is at $200 \mathrm{~Hz}(100 \%$ amplitude, square-wave) and at $200 \mathrm{kHz}$ (10\% amplitude, sine-wave) for CEAS. The two modes of operation result in different laser mode structures (integrated over many modulation cycles) which were measured at a resolution of $0.03 \mathrm{~nm}$ using a $1 \mathrm{~m}$ monochromator (3600 lines $\mathrm{mm}^{-1}$ grating) diode array (Instaspec II) set-up. Wavelength calibration was with three Ne lines and is accurate to $\approx 0.1 \mathrm{~nm}$. The laser emission spectra are illustrated in Fig. 2, along with the $\mathrm{NO}_{3}$ absorption spectrum (Yokelson et al., 1994). In both CEAS and CRD modes, the major emission is between 661.7 and $662 \mathrm{~nm}$, though CEAS shows

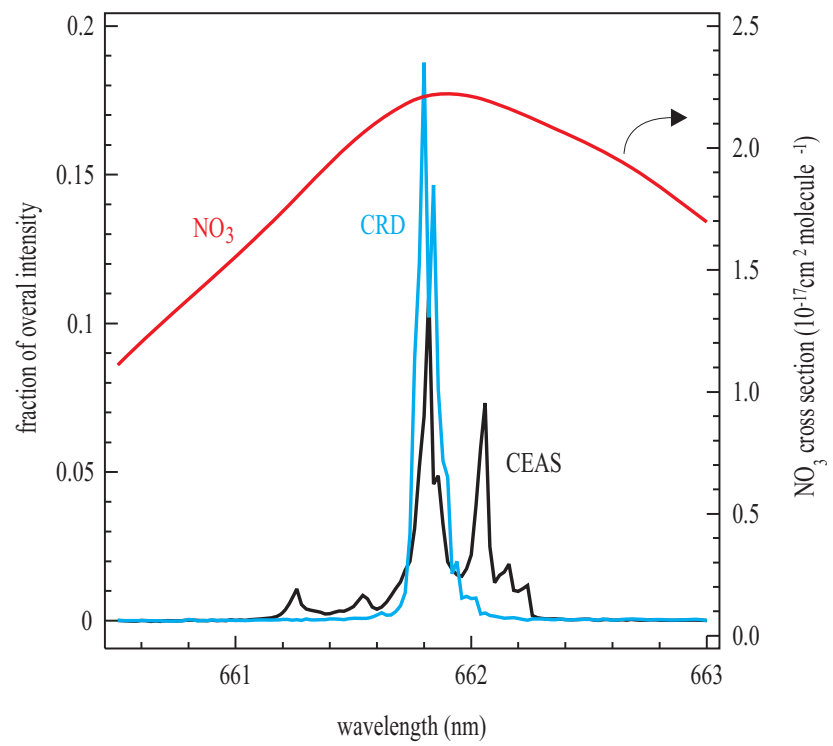

Fig. 2. Laser emission spectra when used in CEAS (black line) or CRD mode (blue line). The spectra are normalised to have an integrated intensity of unity and are compared with a small section of the $\mathrm{NO}_{3}$ absorption spectrum (red curve, right y-axis) at $298 \mathrm{~K}$ (Yokelson et al., 1994).

more complex structure with an additional major mode at $662.06 \mathrm{~nm}$ and several, weak, blue shifted modes. The spectra were observed to be unchanged over a 3 month period prior to and after the $\mathrm{NO}_{3} / \mathrm{N}_{2} \mathrm{O}_{5}$ inter-comparison we report on below. In addition, following coupling of the cavity output to the monochromator, we obtained identical spectra, indicating no significant, preferential excitation of some cavity modes.

The effective cross sections calculated from the overlap of laser emission and $\mathrm{NO}_{3}$ absorption spectrum were $2.17 \times 10^{-17}$ and $2.20 \times 10^{-17} \mathrm{~cm}^{2}$ molecule ${ }^{-1}$ for CEAS and CRD, respectively at $298 \mathrm{~K}$. The temperature dependence of the $\mathrm{NO}_{3}$ cross section was taken from Orphal et al. (2003), the absolute values from Yokelson et al. (1994). The value of $\sigma_{\max }$ (at $\approx 662 \mathrm{~nm}$ ) changes from $2.21 \times 10^{-17} \mathrm{~cm}^{2}$ molecule ${ }^{-1}$ at $22^{\circ} \mathrm{C}$ to $1.65 \times 10^{-17}$ at $95^{\circ} \mathrm{C}$

A small fraction of the laser intensity enters the cavity through a $662 \mathrm{~nm}$ coated dielectric mirror and exits via an identical mirror to be measured by a photomultiplier (PMT) located behind a $662 \mathrm{~nm}$ interference filter $(10 \mathrm{~nm}$ fwhm). The distance between the two dielectric mirrors is $70 \mathrm{~cm}$, curtain flows of zero-air purge the volume extending $\approx 5 \mathrm{~cm}$ in front of the mirrors, protecting them from aggressive trace gases and aerosol deposition.

\subsection{Data acquisition and analysis}

In CRD mode (laser fully modulated at $200 \mathrm{~Hz}$ ) the preamplified PMT signal is digitised and averaged with a 
$100 \mathrm{MHz}, 9$ bit oscilloscope (Tektronix TDS3014B). The sliding mean of 64 ring-down profiles (each 10000 data points) was transferred to a $\mathrm{PC}$ at $3 \mathrm{~Hz}$. The effective time resolution was $\approx 5 \mathrm{~s}$. The cavity loss due to absorption at $662 \mathrm{~nm}$ is calculated from the change in ring down constant in the presence of an absorber and converted to a concentration of $\mathrm{NO}_{3}$ using the effective cross section of $\mathrm{NO}_{3}$ at the experimental temperature and the established relation (Berden et al., 2000; Mazurenka et al., 2005).

$$
\left[\mathrm{NO}_{3}\right]=\frac{\Delta k_{r d} L}{\sigma_{\mathrm{NO} 3} c d}
$$

where $\left[\mathrm{NO}_{3}\right]$ is the concentration of $\mathrm{NO}_{3}\left(\right.$ molecule $\left.\mathrm{cm}^{-3}\right)$, $k_{r d}$ is the ring-down constant (a first-order rate coefficient with units of $\mathrm{s}^{-1}$ ), $\Delta k_{r d}$ is the difference in the ring-down decay constant with and without $\mathrm{NO}_{3}, L$ is the distance between the cavity mirrors $(70 \mathrm{~cm}), d$ is the length of the cavity which is filled with absorber (and $c$ is the speed of light $\approx 2.998 \times 10^{10} \mathrm{~cm} \mathrm{~s}^{-1}$ ). By variation of the mirror purge gas flow whilst monitoring the CEAS signal due to a constant flow of $\mathrm{NO}_{2}$ into the cavity $\left(\mathrm{NO}_{2}\right.$ also absorbs at $\left.662 \mathrm{~nm}\right)$, we were able to calculate a value of $L / d$ of $1.05 \pm 0.03$. Note that the ring-down time constant, $\tau$, is equal to $1 / k_{r d}$ and for a cavity free of absorbing species was typically close to $100 \mu \mathrm{s}$, indicating an effective optical path length of $\approx 27 \mathrm{~km}$.

In CEAS mode, the amplified PMT output is averaged over $200 \mathrm{~ms}$, digitised and transferred to the PC. The change in integrated signal intensity in the presence of an absorber is converted to a concentration of $\mathrm{NO}_{3}$ using Eq. (2) (Berden et al., 2000; Mazurenka et al., 2005).

$$
\left[\mathrm{NO}_{3}\right]=\frac{1-R}{d \sigma_{\mathrm{NO} 3}}\left(\frac{I_{0}}{I}-1\right)
$$

Where $R$ is the mirror reflectivity (obtained from ring-down measurements in the absence of absorbing species) and $I o$ and $I$ are the light intensities exciting the cavity without and with absorber, respectively. The reflectivity is related to $k_{r d}$ and the optical path-length $(l)$ by:

$k_{r d}=\frac{c(1-R)}{L}$ or $l=\frac{d}{(1-R)}$

Note that operation in CEAS mode thus requires knowledge of the reflectivity $(R)$ or the path length $(l)$. Both can be calculated by measuring $k_{r d}$ in the absence of absorber or by adding a known concentration of absorber (with known cross section at the laser wavelength) to the cavity.

In most experiments reported here, although the laser was modulated at $200 \mathrm{~Hz}$ (i.e. for CRD mode), both the CRD and CEAS signal were recorded simultaneously. Spot checks showed the agreement between concentrations of $\mathrm{NO}_{3}$ made using CRD and CEAS modes to be generally excellent $(<5 \%$ deviation) though sometimes larger deviations were observed (see later).

\subsection{Gas flows and titration of $\mathrm{NO}_{3}$}

Air samples are drawn into the instrument through a $\approx 50 \mathrm{~cm}$ long piece of PFA tubing of $9.5 \mathrm{~mm}$ internal diameter, at a (typical) flow rate of 12 litres per minute (SLM). Of this flow, $8 \mathrm{SLM}$ are drawn through a further $18 \mathrm{~cm}$ piece of PFA tubing and Teflon (FEP) coated aluminium incorporating a $22 \mathrm{~mm}$ diameter Teflon membrane filter (pore size 1 or $2 \mu \mathrm{m}$ ) to eliminate particles from the air stream. Following the Teflon filter, the air sample passes into a Teflon coated (FEP 121a), inverted, thermally insulated glass Tpiece (i.d. $1.8 \mathrm{~cm}$ ) which can be heated to $95^{\circ} \mathrm{C}$ using resistive heating wire wrapped at close spacing around the glass (for measurement of $\mathrm{NO}_{3}+\mathrm{N}_{2} \mathrm{O}_{5}$ ) or maintained at ambient temperature (for measurement of $\mathrm{NO}_{3}$ only). The horizontal section of the glass T-piece (length=61 cm) defines the gas flow within the optical cavity, in which the average residence time is $\approx 1 \mathrm{~s}$. The vertical section is long enough to ensure complete titration of $\mathrm{NO}_{3}$ with $\mathrm{NO}$ and/or thermal conversion of $\mathrm{N}_{2} \mathrm{O}_{5}$ to $\mathrm{NO}_{3}$. Temperatures in both vertical and horizontal sections are monitored with thermistors with an accuracy of $0.2^{\circ} \mathrm{C}$. The cavity mirrors are purged with $2 \times 150 \mathrm{sccm}$ of bottled, filtered, zero air.

In both CEAS and CRD modes of operation, the ring down constant or integrated output intensity in the absence of absorbing species (chemical "zero") is measured by adding $\approx 10^{12}$ molecule $\mathrm{cm}^{-3}$ of $\mathrm{NO}$ to the inlet upstream of the Teflon filter. Based on the evaluated rate coefficient for reaction R4 $\left(k_{4}=1.8 \times 10^{-11} \exp (110 / T) \mathrm{cm}^{3}\right.$ molecule $\left.{ }^{-1} \mathrm{~s}^{-1}\right)$ (Atkinson et al., 2007) this amount of NO should result in complete titration of $\mathrm{NO}_{3}$ within $\approx 0.1 \mathrm{~s}$ (3-half lives). This method of determining the baseline signal allows separation of the $\mathrm{NO}_{3}$ signal from other atmospheric absorbers such as $\mathrm{NO}_{2}, \mathrm{O}_{3}$ and $\mathrm{H}_{2} \mathrm{O}$ and is superior to e.g. flushing the cavity with zero air. The importance of this is illustrated in Fig. 3, which shows the optical density (per $\mathrm{cm}$ ) of a number of atmospheric trace gases at typical mixing ratios. Clearly, fluctuating $\mathrm{H}_{2} \mathrm{O}$ mixing ratios could represent a problem if the chemical zero is not measured frequently enough and at the same $\mathrm{H}_{2} \mathrm{O}$ mixing ratio as the $\mathrm{NO}_{3}$ measurement. In addition, we note that adding $\mathrm{NO}$ to air samples containing $\mathrm{O}_{3}$ at typical tropospheric mixing ratios ( $>20 \mathrm{ppbv}$ ) results in removal of $\mathrm{O}_{3}$ and formation of $\mathrm{NO}_{2}$. The effect on the total absorption at $662 \mathrm{~nm}$ is generally small and corrections can be accurately applied (see Sect. 3.3).

\subsection{Raw Data in CEAS/CRD Modes}

A typical set of raw data obtained whilst sampling $\mathrm{NO}_{3}$ containing air from the SAPHIR chamber in CEAS mode is given in Fig. 4 (upper panel). The titration was carried out over a $20 \mathrm{~s}$ period every $100 \mathrm{~s}$ following mixing of $\mathrm{NO}_{2}$ $(\approx 3 \mathrm{ppbv})$ and $\mathrm{O}_{3}(\approx 100 \mathrm{ppbv})$ in the chamber. As the signal integration time is less that the residence time of gas in the cavity, the response of $\mathrm{NO}_{3}$ to addition of $\mathrm{NO}$ is rapid $(\approx 5 \mathrm{~s}$ 

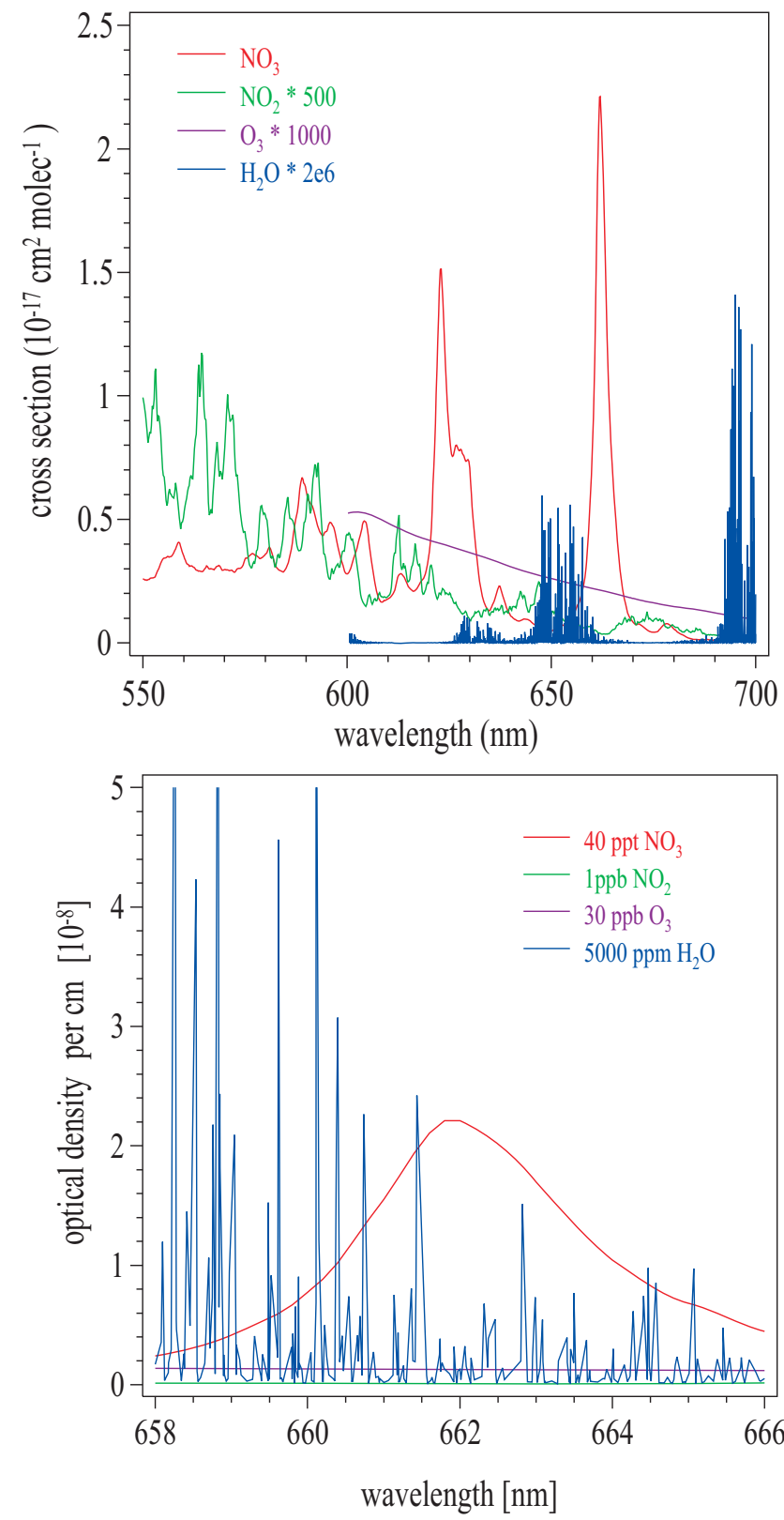

Fig. 3. Upper: $\mathrm{NO}_{3}$ spectrum compared to other "red" absorbers. The absorption coefficients of $\mathrm{NO}_{2}, \mathrm{O}_{3}$ and $\mathrm{H}_{2} \mathrm{O}$ have been scaled upwards as shown. Lower: Result of folding the absorption spectra of $\mathrm{NO}_{3}, \mathrm{NO}_{2}, \mathrm{O}_{3}$ and $\mathrm{H}_{2} \mathrm{O}$ with representative ambient concentrations.

for these experiments at a flow rate of 3 SLM) compared to the duty cycle. The raw CEAS signal as shown in Fig. 4 is an average over $200 \mathrm{~ms}$ and the random noise levels $\left(\left(\Delta I / I_{0}\right)\right.$ of $5-10 \times 10^{-4}$ ) associated with this signal are equivalent to $\approx 1$ pptv of $\mathrm{NO}_{3}$. We note that this noise limited detection limit is similar to that reported for the best pulsed CRD field device which reports e.g. $2 \sigma$ detection limits of $0.2 \mathrm{pptv}$ in $1 \mathrm{~s}$ (Dubé et al., 2006). On the other hand we note that in-
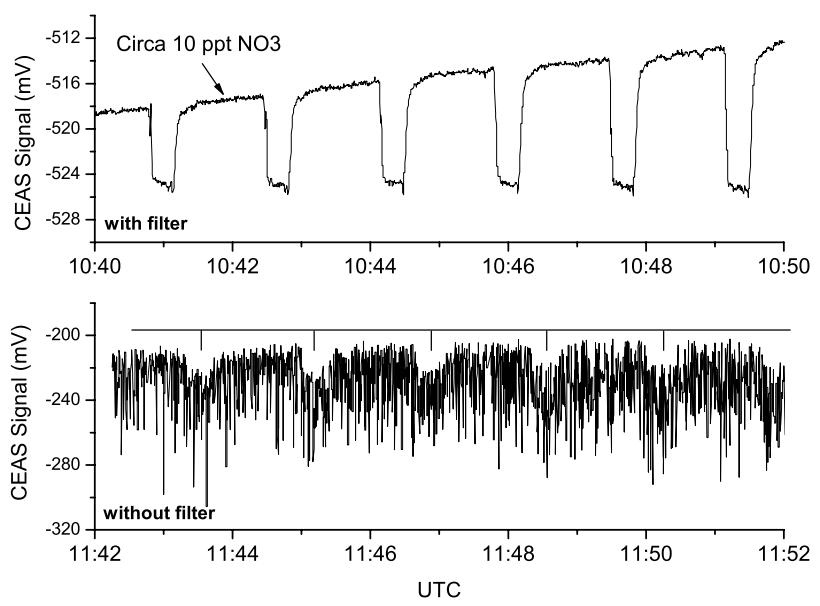

Fig. 4. Upper panel: Raw data obtained in CEAS mode. $\mathrm{NO}_{3}$ was detected following mixing of $\mathrm{NO}_{2}(\approx 3 \mathrm{ppbv})$ and $\mathrm{O}_{3}(\approx 100 \mathrm{ppbv})$ in the SAPHIR chamber at 10:30 UT. The difference in signals with and without $\mathrm{NO}$ titration correspond to concentrations of $\mathrm{NO}_{3}$ of between $\approx 10$ pptv (at 10:40) and 21 pptv of $\mathrm{NO}_{3}$ (at 10:49) as indicated. The total flow was 3 SLM. Lower Panel: As above, data

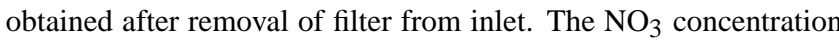
of $\approx 50 \mathrm{pptv}$ is barely detectable above a particle induced "noise" of $\approx 100$ pptv $\mathrm{NO}_{3}$ equivalents. Note that these concentrations have not been corrected for e.g. inlet/filter loss.

creasing the flow rate through the inlet and cavity to 8 SLM resulted in a significant increase in the signal noise, presumably due to turbulence and pressure fluctuations in the cavity. As we show later, operation at 8 SLM is desirable as heterogeneous losses of $\mathrm{NO}_{3}$ can be minimised.

The CEAS signal is dramatically reduced in quality by removal of the particle filter (lower panel) as particle induced noise of $\approx 100$ pptv $\mathrm{NO}_{3}$ equivalents is apparent. Note that the noise is not randomly distributed around the mean signal, but is biased to low values, indicating that individual particles on passage through the cavity cause substantial intensity fluctuations due to light extinction at $662 \mathrm{~nm}$. We note that the air sample extracted from the SAPHIR chamber was for this experiment nominally "particle free" indicating extreme sensitivity of this method to particles.

Raw data obtained in CRD mode is displayed in Fig. 5 which presents a ring-down profile (upper panel) with $k_{r d} \approx 10563 \pm 5 \mathrm{~s}^{-1}$ (errors are $2 \sigma$ statistical) or a ring-down time of $\approx 95 \mu$ s corresponding to an optical path length of $\approx 27 \mathrm{~km}$ (Eq. 3). As mentioned above, the data were obtained by averaging (in the oscilloscope) 64 ring down profiles each of 10000 data points, resulting in a sliding average value over $\approx 5 \mathrm{~s}$. The first $\approx 5 \%$ of the ring-down profile were often non-exponential and were rejected online during data transfer from the oscilloscope and the last 2000 data points were used to establish the signal baseline, which may be distinct from zero due to electrical/optical offsets. Once the baseline was subtracted, $\approx 2000$ data points were analysed by least 

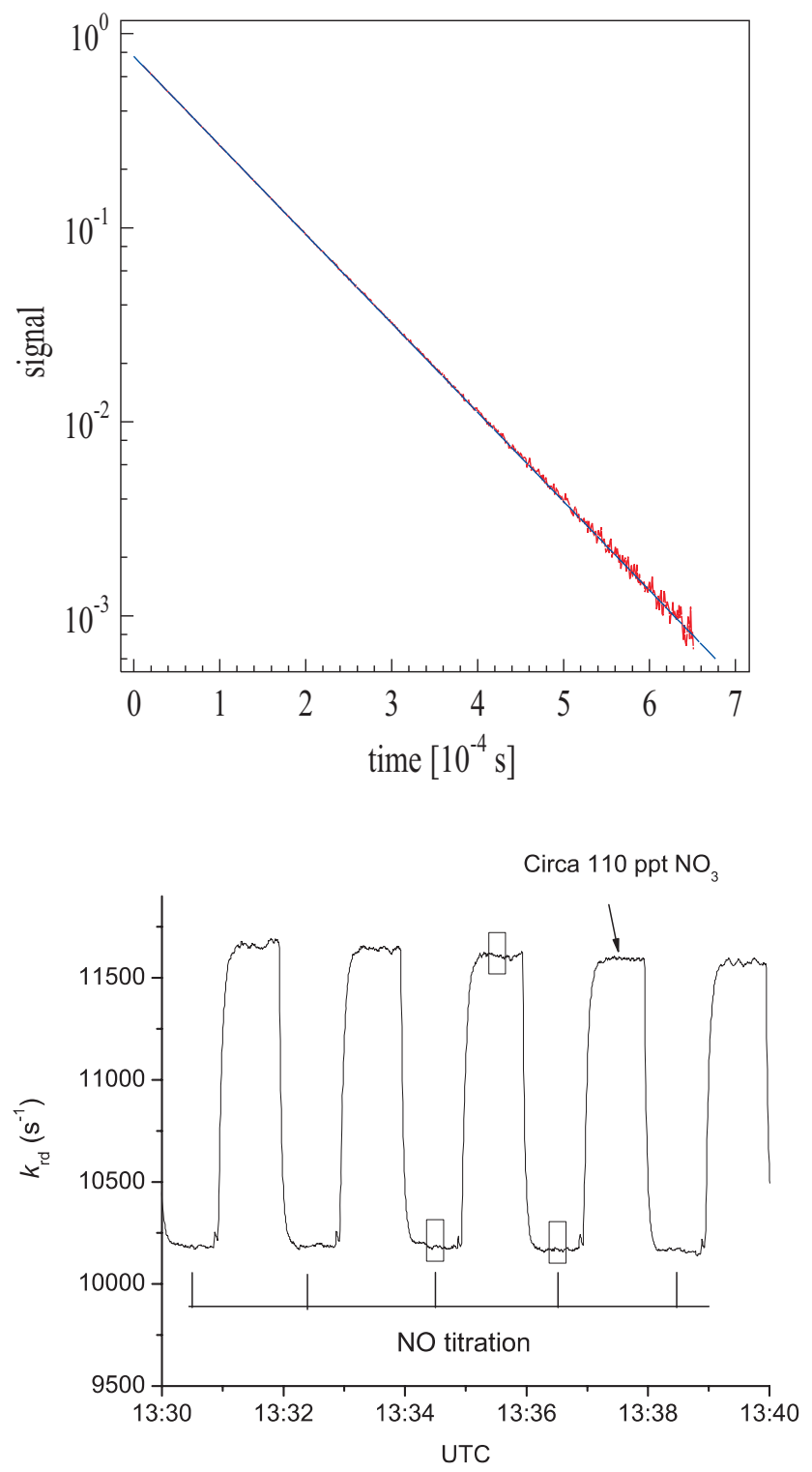

Fig. 5. Upper panel: Raw data obtained in CRD mode. 64 ringdowns were averaged to yield a decay constant of $13732 \pm 5(2 \sigma)$. The ring-down signal extends to time $=0$, but is obscured by the width of the regression line. Lower Panel: $\mathrm{NO}_{3}$ Data obtained whilst sampling $\approx 8$ SLM from the SAPHIR chamber. Values of $\delta k_{r d}$ obtained with and without $\mathrm{NO}$ (see Eq. 2) indicate $\mathrm{NO}_{3}$ is present in the cavity at levels of $\approx 110$ pptv. The ring down constant of $\approx 10200 \mathrm{~s}^{-1}$ during the titration phase indicates optical path length of $\approx 26 \mathrm{~km}$.

squares regression to extract $k_{r d}$ before the next $(5 \mathrm{~s}$ averaged) ring down profile was transferred from the scope. The resulting data density was $\approx 3$ ring down constants per second. When working in CRD mode, a 50\% titration duty cycle was generally used with 1 min measurement followed by 1 min of titration. When performing optimally, $1 \sigma$ random noise levels of $\delta k_{r d}=20 \mathrm{~s}^{-1}$ corresponding to minimum de- tectable changes in the ring-down time $\left(\Delta \tau_{\min }\right)$ of $\approx 0.2 \mu \mathrm{s}$ (in $\approx 5 \mathrm{~s}$ averaging) were achieved, corresponding to $\mathrm{NO}_{3}$ concentrations of $\approx 2$ pptv and defining the detection limit of the device in CRD mode. Our detection limit is thus comparable to the value of $1.4 \mathrm{pptv}$ in $4.6 \mathrm{~s}$ reported by Ayers et al. (2005) for a similar off axis, CRD set up using a CW diode laser. More generally, the detection limit can be expressed as the minimum detectable extinction $\alpha$ (where $\alpha=\Delta k_{r d} L / c d$ ) per integration interval as $=1 \times 10^{-9} \mathrm{~cm}^{-1} \mathrm{~Hz}^{-1 / 2}$.

Although the noise limited detection limit in CEAS operation mode was (at low flows) better than in CRD mode, CEAS suffers from the disadvantage that the optical path length can vary by several percent over a period of hours and thus needs to be determined frequently to avoid systematic error. In addition, an increase in noise in the CEAS signal was observed when the instrument was operated at high flows ( $>3$ SLM). In contrast, the CRD mode is insensitive to laser intensity drifts and the minimum measurable $\Delta k_{r d}$ did not deteriorate significantly when flow rates were increased between 3 and 8 SLM.

\section{Data correction, assessment of systematic errors and detection limit}

The use of an extractive approach for measurement of ambient $\mathrm{NO}_{3}$ or $\mathrm{N}_{2} \mathrm{O}_{5}$ requires knowledge of the transmission efficiency of both species through the inlet lines and the particle filter. We also need to assess systematic errors resulting e.g. from the procedure to titrate $\mathrm{NO}_{3}$. These are discussed in detail below and used to derive the overall uncertainty of the device for measurement of $\mathrm{NO}_{3}$ and $\mathrm{N}_{2} \mathrm{O}_{5}$.

\subsection{Inlet/cavity transmission of $\mathrm{NO}_{3}$ and $\mathrm{N}_{2} \mathrm{O}_{5}$}

Estimation of the loss rates of $\mathrm{NO}_{3}$ during transmission through the inlet tubing and the cavity was made on four separate occasions during the SAPHIR inter-comparison by variation of the flow rate of air drawn through the instrument and thus the residence time. The tests were carried out when stable concentrations of $\mathrm{NO}_{3}$ were observed in the chamber (small corrections were applied to take into account mixing ratio drifts) and with different $\mathrm{NO}_{3}$ concentrations and $\mathrm{NO}_{3} / \mathrm{N}_{2} \mathrm{O}_{5}$ ratios in the chamber. Results from two days are displayed in Fig. 6, in which two different filters were used. From the data displayed, the decay constants obtained were $(8.2 \pm 1.0) \times 10^{-2} \mathrm{~s}^{-1}$ and $(9.1 \pm 2.0) \times 10^{-2} \mathrm{~s}^{-1}$, which, within experimental uncertainty, are identical. Although the inlet and cavity are constructed from Teflon and Teflon-coated glass tubing of slightly different diameter (and thus different flow velocities in different parts of the system) to a first approximation we can use the average loss rate constant $\left(k_{\text {obs }}\right)$ to derive a sticking coefficient $(\gamma$, the per 


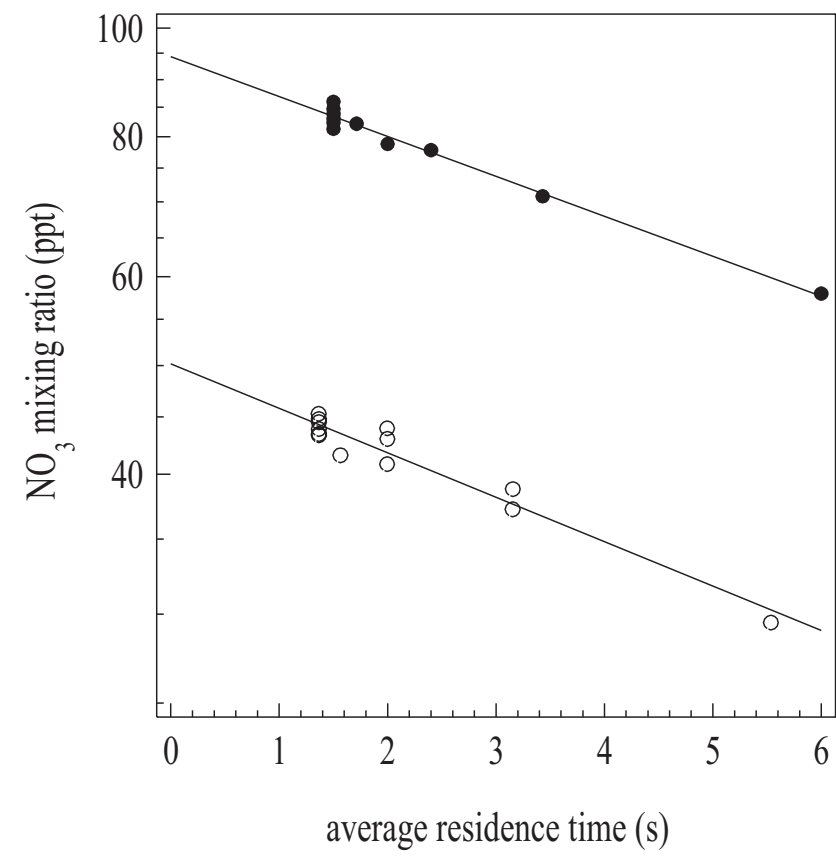

Fig. 6. Determination of $\mathrm{NO}_{3}$ loss in the inlet lines (PFA-Teflon) and cavity (Teflon FEP 121a coated glass). The two datasets displayed were obtained on separate days (open circles on the $21 \mathrm{st}$, solid circles on the 15 th and using two different filters (see text for details). Within experimental uncertainty the decay coefficients were the same.

collision efficiency of removal of $\mathrm{NO}_{3}$ from the gas-phase) for $\mathrm{NO}_{3}$ on Teflon tubing via:

$\gamma=\frac{2 r k_{\mathrm{obs}}}{\bar{c}}$

where $r$ is the average radius of the tubing and $\bar{c}$ the mean molecular velocity of $\mathrm{NO}_{3}\left(32000 \mathrm{~cm} \mathrm{~s}^{-1}\right)$ as derived from the Maxwell expression. With $r=0.75 \mathrm{~cm}$, we derive $\gamma=4 \times 10^{-6}$, indicating that only 4 collisions per million result in removal from the gas-phase. Note that correction for diffusive effects (Brown, 1978) does not change this approximate number significantly.

With a total flow of 8 SLM (corresponding to an average residence time of $\approx 1.5 \mathrm{~s}$ ), the associated correction factor from these two days is 1.14. Correction factors for all 4 days are listed in Table 1. By comparison, use of a 3 SLM flow would result in a correction factor of $\approx 1.4$.

From Table 1 we see that the $\mathrm{NO}_{3}$ inlet loss was fairly constant over a period of 7 days, with an average correction factor of about 1.13 when data from the 14th, 15th and 21st are taken into consideration. The exception is the 20th of June when the flow test was conducted with a large $\left[\mathrm{N}_{2} \mathrm{O}_{5}\right] /\left[\mathrm{NO}_{3}\right]$ ratio in the chamber. On this day, the apparent $\mathrm{NO}_{3}$ loss rate constant was much smaller. This is due to $\mathrm{N}_{2} \mathrm{O}_{5}$ thermal dissociation within the residence time in inlet and cavity $(1.5 \mathrm{~s})$ which disguises the true $\mathrm{NO}_{3}$ loss. At low $\mathrm{N}_{2} \mathrm{O}_{5}$
Table 1. Correction for $\mathrm{NO}_{3}$ transmission through the inlet and cavity.

\begin{tabular}{llll}
\hline Day (in June) & correction factor & {$\left[\mathrm{N}_{2} \mathrm{O}_{5}\right]^{\mathrm{a}}$} & {$\left[\mathrm{NO}_{3}\right]^{\mathrm{a}}$} \\
\hline 14 th & $1.11 \pm 0.05$ & 120 & 60 \\
15 th & $1.14 \pm 0.05$ & 110 & 60 \\
20 th & $1.002 \pm 0.05$ & 3550 & 110 \\
$21 \mathrm{st}$ & $1.14 \pm 0.05$ & 47 & 61 \\
\hline
\end{tabular}

Notes: ${ }^{a}$ Mixing ratio (pptv) in the SAPHIR chamber.

the rate of formation of $\mathrm{NO}_{3}$ via $\mathrm{N}_{2} \mathrm{O}_{5}$ thermal decomposition is small and we measure the "true" $\mathrm{NO}_{3}$ wall loss rate. The appropriate correction factor is thus the larger one. $\mathrm{Nu}-$ merical simulations (Curtis and Sweetenham, 1987) of the $\mathrm{NO}_{3} / \mathrm{N}_{2} \mathrm{O}_{5}$ equilibrium with different $\mathrm{N}_{2} \mathrm{O}_{5} / \mathrm{NO}_{3}$ amounts and ratios were thus performed to assess the size of this effect. The simulations were initiated by reacting $\mathrm{NO}_{2}$ with $\mathrm{O}_{3}$ and allowing the system to approach steady $\mathrm{NO}_{3}$ and $\mathrm{N}_{2} \mathrm{O}_{5}$ concentrations before introducing a $\mathrm{NO}_{3}$ loss. The relative $\mathrm{NO}_{3} / \mathrm{N}_{2} \mathrm{O}_{5}$ concentration was varied by changing the $\mathrm{NO}_{2}$ concentration and the temperature. The simulation results (Table 2) show that, as expected, at high $\mathrm{N}_{2} \mathrm{O}_{5}$, the decay of $\mathrm{NO}_{3}$ due to wall loss is not exponential $\left(\mathrm{NO}_{3}\right.$ is reformed on the time scale of its wall loss) whereas at low $\mathrm{N}_{2} \mathrm{O}_{5}$ it is. This is illustrated by the simulation results displayed in Fig. 7. However, at our short residence times the simple analytical correction gives (within a few percent) the same factor as the full simulation (accounting for $\mathrm{N}_{2} \mathrm{O}_{5}$ thermal dissociation). So, to a good approximation, as long as the residence time is short and temperatures are close to ambient, a single correction factor can be applied. The error on this correction factor is increased to $1.13 \pm 0.1$ to take into account effects such as those discussed above.

It has frequently been shown (see e.g. Simpson, 2003; Aldener et al., 2006) that the loss of $\mathrm{N}_{2} \mathrm{O}_{5}$ through Teflon piping/filters is minor compared to $\mathrm{NO}_{3}$. Nonetheless, when operating in $\mathrm{N}_{2} \mathrm{O}_{5}$ mode (i.e. heated cavity) flow tests similar to those described above showed that the $\mathrm{N}_{2} \mathrm{O}_{5}$ signal was lower at long residence times. Recall that, in this system, $\mathrm{N}_{2} \mathrm{O}_{5}$ is measured as $\mathrm{NO}_{3}$ following thermal conversion before flowing into the hot cavity and thus provides a measure of the sum of $\mathrm{N}_{2} \mathrm{O}_{5}+\mathrm{NO}_{3}$. Losses of $\mathrm{NO}_{3}$ on the heated inlet and cavity walls therefore have to be taken into account to derive a corrected $\mathrm{N}_{2} \mathrm{O}_{5}+\mathrm{NO}_{3}$ summed mixing ratio. Using the same approach as for $\mathrm{NO}_{3}$, the apparent loss rate constant for $\mathrm{N}_{2} \mathrm{O}_{5}$ was determined to be $5.5 \times 10^{-2} \mathrm{~s}^{-1}$, resulting in a correction factor of 1.1 at a flow rate of 8 SLM. This correction is only rigorous in the limit of $\mathrm{N}_{2} \mathrm{O}_{5} / \mathrm{NO}_{3} \rightarrow$ infinity, as it does not take into account the different rate of loss of $\mathrm{NO}_{3}$ and $\mathrm{N}_{2} \mathrm{O}_{5}$ to the walls, or the filter loss of $\mathrm{NO}_{3}$. The correction factor for the measurement of $\mathrm{N}_{2} \mathrm{O}_{5}+\mathrm{NO}_{3}$ was thus determined as $1.1( \pm 0.1)$. 
Table 2. Simulation of correction for $\mathrm{NO}_{3}$ loss.

\begin{tabular}{|c|c|c|c|c|c|}
\hline Case & {$\left[\mathrm{N}_{2} \mathrm{O}_{5}\right]^{\mathrm{a}}$} & {$\left[\mathrm{NO}_{3}\right]^{\mathrm{a}}$} & $\begin{array}{l}\text { simple loss }{ }^{\mathrm{b}} \\
\text { @ } 0.082 \mathrm{~s}^{-1}\end{array}$ & numerical (true) loss & $\delta \mathrm{f}$ (percent) \\
\hline $\begin{array}{l}\text { High } \mathrm{N}_{2} \mathrm{O}_{5} \\
\text { High } \mathrm{NO}_{3} \\
295 \mathrm{~K}\end{array}$ & 5800 & 650 & $\begin{array}{l}650 \rightarrow 575 \\
(f=1.13)\end{array}$ & $\begin{array}{l}650 \rightarrow 585 \\
(f=1.11)\end{array}$ & 2 \\
\hline $\begin{array}{l}\text { High } \mathrm{N}_{2} \mathrm{O}_{5} \\
\text { low } \mathrm{NO}_{3} \\
285 \mathrm{~K}\end{array}$ & 5200 & 132 & $\begin{array}{l}132 \rightarrow 117 \\
(\mathrm{f}=1.13)\end{array}$ & $\begin{array}{l}132 \rightarrow 120 \\
(\mathrm{f}=1.10)\end{array}$ & 3 \\
\hline $\begin{array}{l}\text { low } \mathrm{N}_{2} \mathrm{O}_{5} \\
\text { medium } \mathrm{NO}_{3} \\
295 \mathrm{~K}\end{array}$ & 50 & 145 & $\begin{array}{l}145 \rightarrow 128 \\
(\mathrm{f}=1.13)\end{array}$ & $\begin{array}{l}145 \rightarrow 128 \\
(\mathrm{f}=1.13)\end{array}$ & 0 \\
\hline
\end{tabular}

Notes: ${ }^{a}$ Mixing ratio (pptv) in the SAPHIR chamber. ${ }^{\mathrm{b}}$ After $1.5 \mathrm{~s}$ using a correction factor of 1.13 (assumes exponential decay with $\left[\mathrm{NO}_{3}\right]_{t}=\left[\mathrm{NO}_{3}\right]_{0} \exp \left(-k_{\mathrm{obs}} t\right)$. $\mathrm{f}=$ correction factor at $\mathrm{t}=1.5 \mathrm{~s}$.
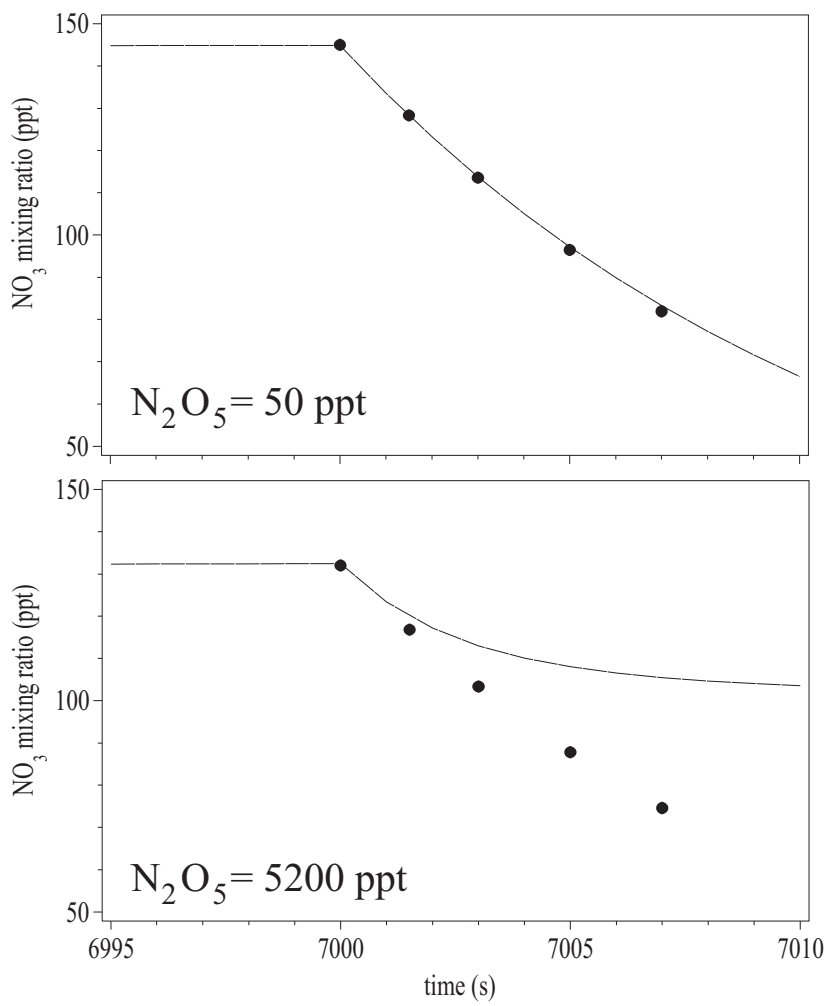

Fig. 7. Simulated losses of $\mathrm{NO}_{3}$ in inlet and cavity. Chemistry initiated with $\mathrm{NO}_{2}$ and $\mathrm{O}_{3}$. The gas mixture enters the inlet after $7000 \mathrm{~s}$ in the chamber. The data points are taken from the analytical expression $\left[\mathrm{NO}_{3}\right]_{t}=\left[\mathrm{NO}_{3}\right]_{0} \exp \left(-k_{\mathrm{obs}} \mathrm{t}\right)$. The solid line is a simulation of the $\mathrm{NO}_{3}$ loss using the same value of $k_{\text {obs }}$ at different $\mathrm{N}_{2} \mathrm{O}_{5}$ mixing ratios.

\subsection{Filter losses of $\mathrm{NO}_{3}$ and $\mathrm{N}_{2} \mathrm{O}_{5}$}

Loss of $\mathrm{NO}_{3}$ during transmission through the filter was tested in the laboratory. Teflon filters with $1 \mu \mathrm{m}$ (Millipore FALPO2500) and $2 \mu \mathrm{m}$ (Pal Teflo R2PJ047) pore sizes were used. Due to flow restriction, the $1 \mu \mathrm{m}$ filters caused a pressure drop of $\approx 30$ mbar when sampling 8 SLM air, whilst use of the $2 \mu \mathrm{m}$ filters resulted in a pressure drop of just $\approx 5$ mbar. A 40 L glass vessel (coated internally with a very thin PFA film and blackened outside) was used as reaction volume in which $\approx 100$ ppbv $\mathrm{O}_{3}$ and $10-20$ ppbv $\mathrm{NO}_{2}$ were mixed and reacted over a period of $\approx 40 \mathrm{~min}$. The exhaust $(250 \mathrm{sccm})$ passed into a heated $\left(\approx 80^{\circ} \mathrm{C}\right)$ Teflon pipe where it resided for $\approx 1.5 \mathrm{~s}$ before being dynamically diluted by a flow of $8000 \mathrm{sccm}$ air and transported into the cavity at room temperature. The final flow contained about 100-200 pptv $\mathrm{NO}_{3}$ at atmospheric pressure (and $<10$ pptv $\mathrm{N}_{2} \mathrm{O}_{5}$ ). The $\mathrm{NO}_{3}$ mixing ratio was measured with and without a filter several times to derive the transmission. Summary data are shown in Fig. 8. Drifts in the $\mathrm{NO}_{3}$ signal, presumably caused by pressure drops/increases when the filters were removed/added and contamination of the inlet by laboratory air whilst open precluded very accurate measurement of the filter transmission. However, it is clear that the filter has a transmission of between 80 and $90 \%$. This is consistent with previously measured $\mathrm{NO}_{3}$ transmission efficiencies of Teflon membrane filters (Aldener et al., 2006). It is also apparent that there is no significant difference between the transmission of the $1 \mu \mathrm{m}$ and $2 \mu \mathrm{m}$ filters, though the latter is preferable as the pressure drop across the filter is smaller. $\mathrm{NO}_{3}$ data sets thus require correction by a factor of $1.18 \pm 0.1$ to take into account loss at the filter.

Loss of $\mathrm{N}_{2} \mathrm{O}_{5}$ during transmission through the filter was tested in a similar manner, the difference being that the exhaust of the reaction volume was not heated and that $\mathrm{N}_{2} \mathrm{O}_{5}$ (with a minor amount of $\mathrm{NO}_{3}$ ) passed through the filter 

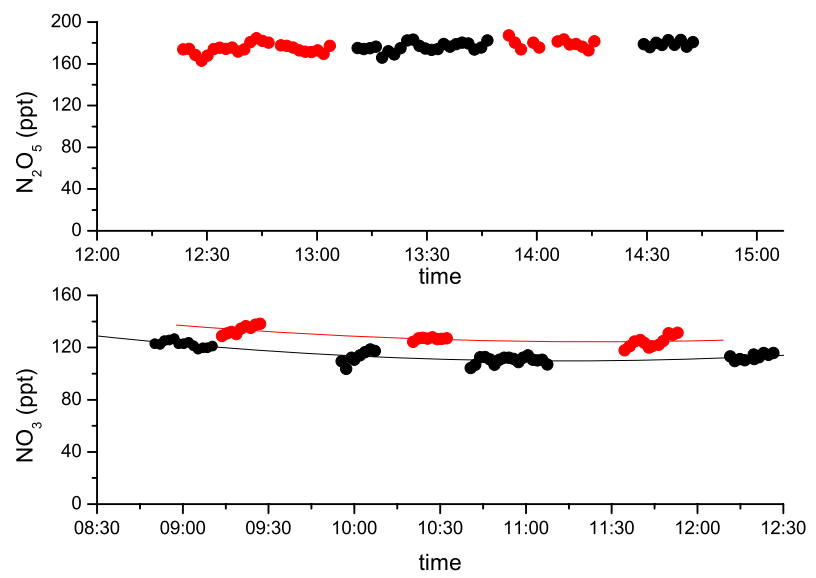

Fig. 8. $\mathrm{N}_{2} \mathrm{O}_{5}$ (upper panel) and $\mathrm{NO}_{3}$ (lower panel) filter transmission tests: Black data points: filter in place, red data points: no filter. The red and black solid lines through the $\mathrm{NO}_{3}$ data are polynomial fits which guide the eye through the slow changes in the initial $\mathrm{NO}_{3}$ concentration. For $\mathrm{NO}_{3}$, filters with both $1 \mu \mathrm{m}$ and $2 \mu \mathrm{m}$ pores were used.

before entering the hot inlet to be converted to $\mathrm{NO}_{3}$. A filter test dataset is presented in Fig. 8. Within the experimental scatter no loss of $\mathrm{N}_{2} \mathrm{O}_{5}$ at the filter could be observed. From the statistical noise we estimate a transmission of $100 \pm 4 \%$. A "correction factor" of $1 \pm 0.04$ may be applied to all $\mathrm{N}_{2} \mathrm{O}_{5}$ data sets to account for filter loss. Note that the filter-transmission efficiencies determined above refer to use of clean filters which had not prior exposure to polluted air. In the course of the SAPHIR inter-comparison it was noted that large aerosol loadings could reduce the filter transmission over the course of less than 1 hour (Dorn et al., 2008), suggesting that frequent changing of the filter is key to accurate concentration measurement. Using the same filters, Fuchs et al. (2008) suggest that filter change every hour is adequate for typical aerosol loadings.

\section{3 $\mathrm{NO}_{2}$ impurities and $\mathrm{NO}+\mathrm{O}_{3}$ reaction during titration}

The derivation of the "chemical zero" was conducted by titrating $\mathrm{NO}_{3}$ with NO. Typically, $3 \mathrm{sccm}$ of a $100 \mathrm{ppmv}$ mix of $\mathrm{NO} / \mathrm{N}_{2}$ was added to the total flow of $8000 \mathrm{sccm}$ to result in a concentration of $\mathrm{NO}$ of approximately $10^{12}$ molecule $\mathrm{cm}^{-3}$ (40 ppbv). $\mathrm{NO}_{2}$ impurity at the $1 \%$ level (this is easily achieved by trap-to-trap distillation of the NO sample) would then result in $1 \times 10^{10}$ molecule $\mathrm{cm}^{-3}$ $\mathrm{NO}_{2}$ or $1 \times 10^{6} \mathrm{NO}_{3}(0.05 \mathrm{pptv})$ equivalents in the cavity. This amount of $\mathrm{NO}_{2}$ is thus too low to warrant correction. Similarly, although the reaction of $\mathrm{NO}_{3}$ with $\mathrm{NO}$ generates two $\mathrm{NO}_{2}$ molecules, the ratio of cross sections of $\mathrm{NO}_{3}$ and $\mathrm{NO}_{2}\left(\approx 10^{4}\right)$ means that this effect is not significant. $\mathrm{NO}$ can however be converted to $\mathrm{NO}_{2}$ if the ambient air contains sufficient $\mathrm{O}_{3}$. Taking $\mathrm{O}_{3}=100 \mathrm{ppbv}$ and $k$
Table 3. Corrections to CRD data and assessment of uncertainty.

\begin{tabular}{|c|c|c|}
\hline Correction/errors for: & $\mathrm{NO}_{3}$ & $\mathrm{NO}_{3}+\mathrm{N}_{2} \mathrm{O}_{5}$ \\
\hline Filter & $1.18 \pm 0.1(8.5 \%)$ & $1.00 \pm 0.04(4 \%)$ \\
\hline Inlet/cavity loss ${ }^{b}$ & $1.13 \pm 0.1(8.9 \%)$ & $1.1 \pm 0.1(9.1 \%)$ \\
\hline Cavity length & $1.05 \pm 0.03$ & $1.05 \pm 0.03(2.9 \%)$ \\
\hline Cross section of $\mathrm{NO}_{3}$ & $5 \% \mathrm{c}$ & $8 \% \mathrm{~d}$ \\
\hline $\begin{array}{l}\text { Reaction of } \mathrm{NO} \text { with } \mathrm{O}_{3} \\
\text { total }\end{array}$ & $\begin{array}{l}<1 \mathrm{pptv} \\
14 \%\end{array}$ & $\begin{array}{l}<1 \mathrm{pptv} \\
13 \%\end{array}$ \\
\hline
\end{tabular}

Notes: ${ }^{a}$ Only applicable to a fresh filter. The transmission of a contaminated filter was observed to decrease to as low as $\approx 50 \%$.

$\mathrm{b}$ at a flow rate of $8 \mathrm{SLM}$ and cavity residence time of about $1.5 \mathrm{~s}$. c at $295 \mathrm{~K},{ }^{\mathrm{d}}$ at $370 \mathrm{~K}$.

$\left(\mathrm{NO}+\mathrm{O}_{3}\right)=1.9 \times 10^{-14} \mathrm{~cm}^{3}$ molecule ${ }^{-1} \mathrm{~s}^{1}$ and an average reaction time of $1.5 \mathrm{~s}$ we can calculate that only $3 \mathrm{ppbv}$ of $\mathrm{O}_{3}$ are removed (and $3 \mathrm{ppbv}$ of $\mathrm{NO}_{2}$ are generated). As the $\mathrm{NO}_{2}$ cross section is larger (factor 2) than the $\mathrm{O}_{3}$ cross section at $662 \mathrm{~nm}$, the overall correction (in terms of $\mathrm{NO}_{3}$ equivalents) is 0.3 pptv which can be a significant correction only at low $\mathrm{NO}_{3}$ mixing ratios.

3.4 Estimation of detection limit and total uncertainty of prototype device

When working in CRD mode, random fluctuations in the ring down constant result in a detection limit of 2 pptv $(5 \mathrm{~s}$ averaged data) for both $\mathrm{NO}_{3}$ and $\mathrm{NO}_{3}+\mathrm{N}_{2} \mathrm{O}_{5}$. The accuracy of the measurement is determined by systematic errors in the absorption cross section of $\mathrm{NO}_{3}$, errors in the correction for filter loss, inlet transmission and effective absorption path (taking purged volumes into account). The correction factors (and associated errors), which are different for $\mathrm{NO}_{3}$ and $\mathrm{N}_{2} \mathrm{O}_{5}+\mathrm{NO}_{3}$ are listed in Table 3. The overall uncertainty of the $\mathrm{NO}_{3}$ measurement using $\mathrm{CRD}$ mode is estimated at about $14 \%$, though at very low $\mathrm{NO}_{3}$ concentrations and high ambient $\mathrm{O}_{3}$ concentrations the effect of $\mathrm{NO}_{2}$ formation in the reaction of $\mathrm{NO}+\mathrm{O}_{3}$ needs to be taken into account. Typically this will be less than 1 pptv as shown in Table 3 and discussed elsewhere in the manuscript. The major source of systematic error in the measurement of both ambient $\mathrm{NO}_{3}$ and $\mathrm{N}_{2} \mathrm{O}_{5}$ is thus the transmission of both trace gases through the inlet and filter, both of which can become chemically reactive due to deposition of aerosols. As shown in Table 4, our detection limit of 2 pptv $\mathrm{NO}_{3}$ in $5 \mathrm{~s}$ sampling interval compares well with the present generation of cavity based $\mathrm{NO}_{3}$ instruments, which use a variety of light sources including pulsed tuneable dye lasers, LEDs and Xenon lamps. We expect that the planned improvements to the instrument (see Sect. 5) will further reduce both our LOD and uncertainty. Due to variability in e.g. optical path-lengths, lamp and spectrograph 
Table 4. Limits of Detection (LOD) of present generation, cavity based $\mathrm{NO}_{3}$ field instruments.

\begin{tabular}{lll}
\hline & Method & LOD $\left(\mathrm{NO}_{3}\right)$ \\
\hline This work & OA-CRD, LD $^{\mathrm{a}}$ & 2 pptv $(5 \mathrm{~s})$ \\
Meinen et al., 2008 & CEAS-LED $^{\mathrm{b}}$ & 6 pptv $(360 \mathrm{~s})^{\mathrm{f}}$ \\
Nakayama et al., 2008 & CRDS-PDL $^{\mathrm{c}}$ & 1.5 pptv $(100 \mathrm{~s})$ \\
Venables et al., 2006 & IBB-CEAS $^{\mathrm{d}}$ & 4 pptv $(60 \mathrm{~s})$ \\
Bitter et al., 2005 & BB-CRDS $^{\mathrm{e}}$ & 1 pptv $(100 \mathrm{~s})$ \\
Dubé et al., 2006 & CRDS-PDL $^{\mathrm{c}}$ & 0.2 pptv $(1 \mathrm{~s})$ \\
Ayers et al., 2005 & OA-CRD, LD $^{\mathrm{a}}$ & 2 pptv $(25 \mathrm{~s})^{\mathrm{g}}$ \\
Simpson, 2003 & & \\
\hline
\end{tabular}

Notes: ${ }^{a}$ Off Axis Cavity Ring Down using a 662 nm laser diode. b Cavity Enhanced Absorption Spectroscopy using a LED as light source. ${ }^{\mathrm{c}}$ Cavity Ring Down using a pulsed dye laser at $\approx 662 \mathrm{~nm}$. $\mathrm{d}$ Incoherent Broad Band Cavity Enhanced Absorption Spectroscopy using a Xe-lamp as light source. e Cavity Ring Down using a pulsed, Broad Band dye laser. ${ }^{\mathrm{f}}$ Varied between 6.3 and 13 pptv. ${ }^{\mathrm{g}}$ Detection limit reported for $\mathrm{N}_{2} \mathrm{O}_{5}$.

types etc., detection limits reported by long-path DOAS instruments for $\mathrm{NO}_{3}$ vary greatly from group-to-group but usually report a LOD between to 0.5 and 5 pptv for $30 \mathrm{~s}$ to 5 mins of spectral averaging (Carslaw et al., 1997; Ambrose et al., 2007).

We have indicated that the random noise associated with the CEAS measurement is less than that for CRD so that, hypothetically, a detection limit of $1 \mathrm{pptv}$ in less than $1 \mathrm{~s}$ could be achieved. However, this precision was only observed when the instrument was operated at low flow rates, which resulted in significant inlet loss of the $\mathrm{NO}_{3}$ radical and loss of accuracy. In addition, the CEAS measurement can suffer from systematic bias due to drift in laser intensity between titrations and we frequently observed sporadic drifts in the cavity output intensity that corresponded to $\approx 5-10 \mathrm{pptv}$ equivalents of $\mathrm{NO}_{3}$ over periods of a minute. Fluctuations in both stray light reaching the PMT (or slow electronic drifts) and spurious laser emissions can contribute to intensity fluctuations in CEAS mode. These issues do not impact CRD measurements as ring down profiles are measured over very short timescales $(200 \mu \mathrm{s})$ and the analysis does not consider the first few $\mu \mathrm{s}$ in which light of inappropriate wavelengths is rejected from the cavity. In addition, when operated in pure CEAS mode (10\% current modulation) we do not measure the ring-down time and thus the path length frequently, so that drifts in this parameter propagate directly into the concentration derived.

For the reasons outlined above, despite its lower sensitivity for this instrument, the datasets described below were obtained in CRD mode (i.e. 100\% current modulation at $200 \mathrm{~Hz}$ ). For comparison we also took the CEAS signal, which is still available in this mode of operation, but with a reduced duty cycle of $50 \%$.

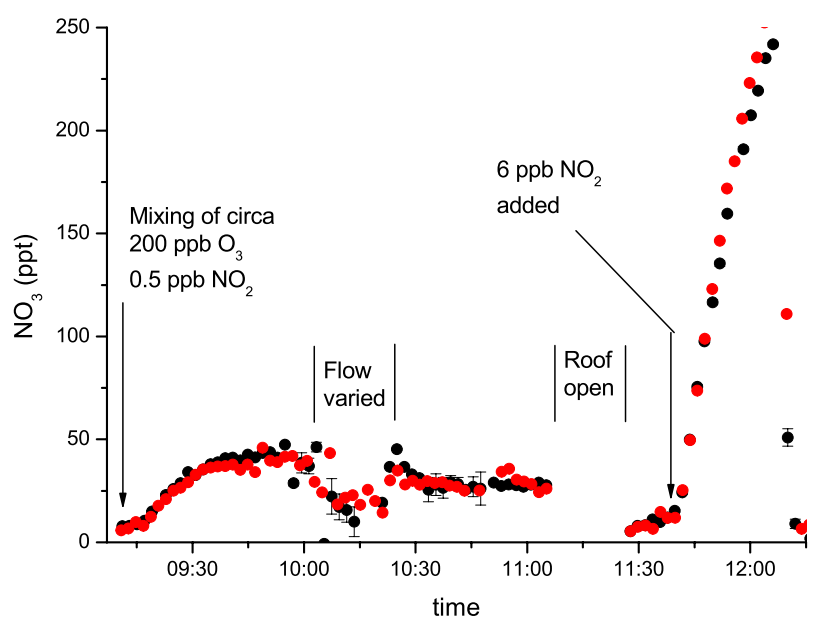

Fig. 9. Comparison of $\mathrm{NO}_{3}$ measurements at the SAPHIR chamber using CRD analysis (red data points) and CEAS analysis (black data points). Error bars are $1 \sigma$ statistical, based on uncertainty in measurements of $I, I_{0}$ and $\Delta k_{r d}$ (see Eqs. 2 and 3).

\section{Exemplary measurements of $\mathrm{NO}_{3}$ and $\mathrm{N}_{2} \mathrm{O}_{5}$}

The performance of the device is best illustrated with $\mathrm{NO}_{3}$ measurements taken either in ambient air or at the SAPHIR chamber. Figure 9 shows a $\approx 4 \mathrm{~h}$ dataset taken on the 13 th of June at the SAPHIR chamber. Note that the dataset has been corrected for inlet and filter loss as described above. The formation of $\mathrm{NO}_{3}$ was initiated by the mixing of $\approx 200 \mathrm{ppbv}$ of $\mathrm{O}_{3}$ and $0.5 \mathrm{ppbv}$ of $\mathrm{NO}_{2}$ in the dark chamber at $\approx 09: 05$ (UTC). $\mathrm{NO}_{3}$ increased over the next $\approx 40 \mathrm{~min}$ before production and loss rates roughly balanced to result in a quasi stable mixing ratio. At this point the inlet and cavity flow rates were varied to check the transmission of the sampling lines for $\mathrm{NO}_{3}$. The large variations (reductions) in mixing ratio between $\approx 10: 05$ and 10:20 highlight the importance of characterising inlet losses and maintaining high flow rates (short residence times). The chamber roof was open or partially open between 11:15 and 11:24 so that no $\mathrm{NO}_{3}$ was observed. After closing the roof and refuelling with $6 \mathrm{ppbv}$ of $\mathrm{NO}_{2}$ at $\approx 11: 40$ an strong increase in $\mathrm{NO}_{3}$ was observed, with maximum values of $\approx 250 \mathrm{pptv}$ reached at 12:06, after which the chamber was opened again. Although the device was operated in CRD mode ( $200 \mathrm{~Hz}$ laser modulation) both CRD and CEAS signals were acquired and evaluated according to Eqs. (1) and (2). The measurement/titration cycle was carried out at an interval of $1 \mathrm{~min}$, so that $5 \mathrm{~s}$ averaged data are generated at a rate of 1 data point per $2 \mathrm{~min}$. The ring down time constant in the absence of $\mathrm{NO}_{3}$ was used to calculate the optical path length in the CEAS measurements. There is clearly very good agreement between the two datasets, though there are indications of a slight deviation at higher mixing ratios whereby the CRD analysis results in the larger value. Analysis of several other datasets revealed that when 
deviations between CRD and CEAS occurred the CRD result was always higher, though the difference never exceeded $10 \%$. One possible explanation is the detection of amplified spontaneous emission from the diode laser which (depending on wavelength) may transmit the cavity efficiently and contribute to the overall integrated intensity signal in CEAS. In CRD mode light of the "wrong" wavelength will leave the cavity with a ring-down time on much shorter time-scale than $662 \mathrm{~nm}$ light and as we reject the first few percent of the decay for analysis would not influence the measurement of $k_{r d}$. Such CEAS-specific problems can be minimised by use of an narrow band interference filter in front of the photomultiplier which is matched to the mirror transmission curve. We also note that varying electrical offsets (caused e.g. by changing temperature of the PMT or other data acquisition electronics) may result in falsification of the CEAS data analysis if the zero signal (i.e. when the laser light is blocked) is not measured occasionally. This would appear to be the most likely explanation for the differences in CEAS and CRD sometimes observed in our datasets. We note that a comparison of our CRD data for $\mathrm{NO}_{3}$ and $\mathrm{N}_{2} \mathrm{O}_{5}$ with those of several other instruments operated at the SAPHIR chamber showed very good agreement, as will be discussed in publications in preparation (Apodaca et al., 2008; Dorn et al., 2008).

A dataset (this time $\mathrm{N}_{2} \mathrm{O}_{5}$ measurements) obtained in ambient air is displayed in Fig. 10. The measurements were conducted on the night of the 5-6 October 2007 by sampling air (8 SLM) through 1/4" Teflon tubing outside of the laboratory window on the 2 nd storey (height $\approx 15 \mathrm{~m}$ ) at the Max-Planck building. The appropriate correction factor for transmission through the Teflon was calculated from the measured loss rate in PFA tubing described above. Measurements were actually performed on a number of nights from the Max-Planck building, but $\mathrm{N}_{2} \mathrm{O}_{5}$ was seen only occasionally. The proximity of the institute to several busy motorways results in large local $\mathrm{NO}$ mixing ratios, which frequently titrate $\mathrm{O}_{3}$ at night so that $\mathrm{NO}_{3}$ (and $\mathrm{N}_{2} \mathrm{O}_{5}$ ) are not detectable. $\mathrm{NO}_{2}$ and $\mathrm{O}_{3}$ mixing ratios on the 5-6 October are also plotted in Fig. 10. They were taken from the closest air quality monitoring station $(\approx 5 \mathrm{~km}$ away from the MPI) and indicate that conditions were favourable for $\mathrm{NO}_{3}$ formation. Relatively high $\left[\mathrm{NO}_{2}\right]$ (10-30 ppbv) and $\mathrm{O}_{3}$ at $20 \pm 10 \mathrm{ppbv}$ resulted in large rates of $\mathrm{NO}_{3}$ production, whereas high $\left[\mathrm{NO}_{2}\right]$ and temperatures close to $6-8^{\circ} \mathrm{C}$ favoured the conversion of $\mathrm{NO}_{3}$ to $\mathrm{N}_{2} \mathrm{O}_{5}$, so that $\mathrm{N}_{2} \mathrm{O}_{5}$ would be dominant. Indeed, $\mathrm{N}_{2} \mathrm{O}_{5}$ was detectable shortly prior to local sunset and reached a maximum mixing ratio of almost $100 \mathrm{pptv}$ at $02: 00$ on the 6 th. The large variability in the $\mathrm{N}_{2} \mathrm{O}_{5}$ signal (especially between 22:00 and 24:00) may be due to slight changes in wind direction resulting in sampling of air masses with different chemical history/aerosol loading or due to variable loss rates to e.g. the MPI building (the inlet protruded only $\approx 50 \mathrm{~cm}$ from the outside wall) and surrounding architecture. The high $\mathrm{N}_{2} \mathrm{O}_{5}$ mixing ratio did not persist through the night, but decreased between 3 a.m. and sunrise. The accompanying growth in NO
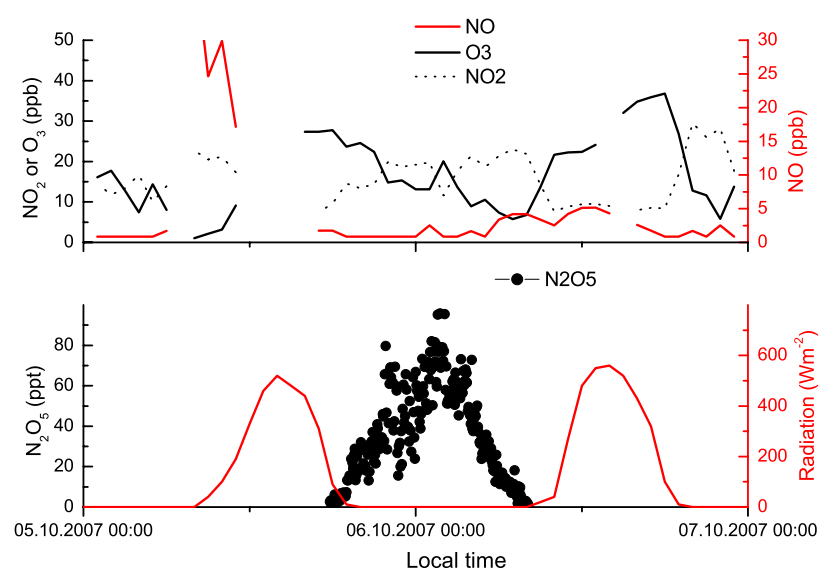

Fig. 10. Upper panel: $\mathrm{O}_{3}, \mathrm{NO}$ and $\mathrm{NO}_{2}$ mixing ratios reported by the local air monitoring site $(\approx 5 \mathrm{~km}$ distance from the MPI building). Lower panel: Data points (left y-axis): $\mathrm{N}_{2} \mathrm{O}_{5}\left(+\mathrm{NO}_{3}\right)$ mixing ratios outside the MPI-building on the night of 5th-6th of October 2007. The solid lines (right y-axis) are global radiation taken from the measurement station of the local (in the state of Hesse) environmental and geological agency.

(and reduction in $\mathrm{O}_{3}$ ) during this time may indicate that increases in local NO may have been responsible for the removal of $\mathrm{NO}_{3}$.

\section{Conclusions and outlook}

We have designed, constructed and tested a new instrument for ambient $\mathrm{NO}_{3} / \mathrm{N}_{2} \mathrm{O}_{5}$ measurements. The first field deployment and participation at an $\mathrm{NO}_{3} / \mathrm{N}_{2} \mathrm{O}_{5}$ inter-comparison have shown that the device can be operated at detection limits of a few pptv in a few seconds, which is adequate for measurement of these trace gases under most conditions. Future improvements to the device will include the capability to measure both $\mathrm{NO}_{3}$ and $\mathrm{N}_{2} \mathrm{O}_{5}$ simultaneously in two independent detection axes using a single laser diode. Data acquisition rates (and instrument weight) will be improved by replacement of the digital oscilloscope with a PC dataacquisition card, resulting in improved detection limits. The laser emission (both before entering and exiting the cavity) will be checked in the field by use of a small, high resolution spectrograph in order to reduce uncertainty associated with e.g. cavity adjustment dependent changes in the effective $\mathrm{NO}_{3}$ cross-section. The irises in front of the laser (to prevent reflected light from first cavity mirror entering the laser diode during adjustment) will be replaced by an optical isolator to increase the power throughput. Initial tests have showed that a factor 3 or more gain in light intensity is achievable. It is also planned to work with shorter gas residence times in the inlet and cavity to reduce $\mathrm{NO}_{3}$ losses (Fuchs et al., 2008) and to improve the duty cycle so that at only $10 \mathrm{~s}$ of each minute sampling time is dedicated to 
the titration of $\mathrm{NO}_{3}$. A major limitation at present is the requirement to manually change the aerosol particle filter at regular intervals through the night. This task will in future be automated (Dubé et al., 2006) to preserve high transmission efficiencies of $\mathrm{N}_{2} \mathrm{O}_{5}$ and $\mathrm{NO}_{3}$. Indeed, we foresee that the instrument will operate in fully automated mode to allow prolonged measurements at remote locations and implementation in space/operator limited aircraft platforms.

Acknowledgements. We thank T. Brauers and H.-P. Dorn for organising the $\mathrm{NO}_{3}-\mathrm{N}_{2} \mathrm{O}_{5}$ inter-comparison at the SAPHIR environmental chamber in Jülich. We also thank the staff at Jülich and the other participants at the inter-comparison for their technical support and encouragement. We also extend our thanks to G. W. Harris, who encouraged us to construct the instrument.

Edited by: M. D. Andres Hernandez

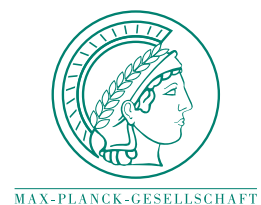

This Open Access Publication is financed by the Max Planck Society.

\section{References}

Aldener, M., Brown, S. S., Stark, H., Williams, E. J., Lerner, B. M., Kuster, W. C., Goldan, P. D., Quinn, P. K., Bates, T. S., Fehsenfeld, F. C., and Ravishankara, A. R.: Reactivity and loss mechanisms of $\mathrm{NO}_{3}$ and $\mathrm{N}_{2} \mathrm{O}_{5}$ in a polluted marine environment: Results from in situ measurements during New England Air Quality Study 2002, J. Geophys. Res., 111, D23S73, doi:10.1029/2006JD007252, 2006.

Ambrose, J. L., Mao, H., Mayne, H. R., Stutz, J., Talbot, R., and Sive, B. C.: Nighttime nitrate radical chemistry at Appledore island, Maine during the 2004 international consortium for atmospheric research on transport and transformation, J. Geophys. Res., 112, D21302, doi:10.1029/2007JD008746, 2007.

Apodaca, R. L., Simpson, W. R., Brauers, T., Brown, S. S., Cohen, R. C., Crowley, J., Dorn, H. P., Dubé, W. P., Fry, J., Fuchs, H., Haseler, R., Heitmann, U., Kato, S., Kajii, Y., Kiendler-Scharr, A., Labazan, I., Matsumoto, J., Nishida, S., Tillmann, R., Rohrer, F., Rollings, A.W., Schlosser, E., Schuster, G., Tillmann, R., Wahner, A., Wegener, R., and Wooldridge, P. J.: Intercomparison of $\mathrm{N}_{2} \mathrm{O}_{5}$ sensors using SAPHIR reaction chamber, Atmos. Chem. Phys. Discuss., in preparation, 2008.

Atkinson, R., Baulch, D. L., Cox, R. A., Crowley, J. N., Hampson, R. F., Hynes, R. G., Jenkin, M. E., Kerr, J. A., Rossi, M. J., and Troe, J.: IUPAC Subcommittee for gas kinetic data evaluation. Evaluated kinetic data: http://www.iupac-kinetic.ch.cam.ac.uk/, 2007.

Ayers, J. D., Apodaca, R. L., Simpson, W. R., and Baer, D. S.: Offaxis cavity ringdown spectroscopy: application to atmospheric nitrate radical detection, Appl. Opt., 44, 7239-7242, 2005.

Bakhirkin, Y. A., Kosterev, A. A., Roller, C., Curl, R. F., and Tittel, F. K.: Mid-infrared quantum cascade laser based off-axis integrated cavity output spectroscopy for biogenic nitric oxide detection, Appl. Opt., 43, 2257-2266, 2004.
Ball, S. M., Povey, I. M., Norton, E. G., and Jones, R. L.: Broadband cavity ringdown spectroscopy of the $\mathrm{NO}_{3}$ radical, Chem. Phys. Lett., 342, 113-120, 2001.

Berden, G., Peeters, R., and Meijer, G.: Cavity ring-down spectroscopy: Experimental schemes and applications, Int. Rev. Phys. Chem., 19, 565-607, 2000.

Bitter, M., Ball, S. M., Povey, I. M., and Jones, R. L.: A broadband cavity ringdown spectrometer for in-situ measurements of atmospheric trace gases, Atmos. Chem. Phys., 5, 2547-2560, 2005, http://www.atmos-chem-phys.net/5/2547/2005/.

Brown, R. L.: Tubular flow reactors with first-order kinetics, J. Res. Nat. Bur. Standards, 83, 1-8, 1978.

Brown, S. S.: Absorption spectroscopy in high-finesse cavities for atmospheric studies, Chem. Rev., 103, 5219-5238, 2003.

Brown, S. S., Stark, H., Ciciora, S. J., McLaughlin, R. J., and Ravishankara, A. R.: Simultaneous in situ detection of atmospheric $\mathrm{NO}_{3}$ and $\mathrm{N}_{2} \mathrm{O}_{5}$ via cavity ring-down spectroscopy, Rev. Sci. Inst., 73, 3291-3301, 2002.

Brown, S. S., Stark, H., Ciciora, S. J., and Ravishankara, A. R.: Insitu measurement of atmospheric $\mathrm{NO}_{3}$ and $\mathrm{N}_{2} \mathrm{O}_{5}$ via cavity ringdown spectroscopy, Geophys. Res. Lett., 28, 3227-3230, 2001.

Brown, S. S., Stark, H., and Ravishankara, A. R.: Applicability of the steady state approximation to the interpretation of atmospheric observations of $\mathrm{NO}_{3}$ and $\mathrm{N}_{2} \mathrm{O}_{5}$, J. Geophys. Res., 108, 4539, doi:10.1029/2003JD003407, 2003.

Carslaw, N., Plane, J. M. C., Coe, H., and Cuevas, E.: Observations of the nitrate radical in the free troposphere at Izana de Tenerife, J. Geophys. Res., 102, $10613-10622,1997$.

Curtis, A. R. and Sweetenham, W. P.: Facsimile, AERE, Report R-12805, 1987.

Dorn, H. P., Apodaca, R. L., Ball, S. M., Brauers, T., Brown, S. S., Crowley, J. N., Dube, W. P., Fuchs, H., Häseler, R., Heitmann, U., Jones, R. L., Labazan, I., Langridge, J., Meinen, J., Platt, U., Pöhler, D., Rohrer, F., Ruth, A. A., Schlosser, E., Schuster, G., Shillings, A., Simpson, W., Thieser, J., Varma, R., Venables, D., and Wahner, A.: Intercomparison of $\mathrm{NO}_{3}$ radical detection instruments in the Atmosphere Simulation Chamber SAPHIR., Atmos. Chem. Phys. Discuss., in preparation, 2008.

Dubé, W. P., Brown, S. S., Osthoff, H. D., Nunley, M. R., Ciciora, S. J., Paris, M. W., McLaughlin, R. J., and Ravishankara, A. R.: Aircraft instrument for simultaneous, in situ measurement of $\mathrm{NO}_{3}$ and $\mathrm{N}_{2} \mathrm{O}_{5}$ via pulsed cavity ring-down spectroscopy, Rev. Sci. Inst., 77, 034101, doi:10.1063/1.2176058, 2006.

Fuchs, H., Dubé, W. P., Ciciora, S. J., and Brown, S. S.: Determination of inlet transmission and conversion efficiencies for in situ measurements of the nocturnal nitrogen oxides, $\mathrm{NO}_{3}, \mathrm{~N}_{2} \mathrm{O}_{5}$ and $\mathrm{NO}_{2}$ via pulsed cavity ring-down spectroscopy, Anal. Chem., 80, 6010-6017, 2008.

Geyer, A., Alicke, B., Mihelcic, D., Stutz, J., and Platt, U.: Comparison of tropospheric $\mathrm{NO}_{3}$ radical measurements by differential optical absorption spectroscopy and matrix isolation electron spin resonance, J. Geophys. Res., 104, 26 097-26 105, 1999.

Kasyutich, V. L., Canosa-Mas, C. E., Pfrang, C., Vaughan, S., and Wayne, R. P.: Off-axis continuous-wave cavity-enhanced absorption spectroscopy of narrow-band and broadband absorbers using red diode lasers, Appl. Phys. B., 75, 755-761, 2002.

King, M. D., Dick, E. M., and Simpson, W. R.: A new method for the atmospheric detection of the nitrate radical $\left(\mathrm{NO}_{3}\right)$, Atmos. Environ., 34, 685-688, 2000. 
Matsumoto, J., Imai, H., Kosugi, N., and Kaji, Y.: In situ measurement of $\mathrm{N}_{2} \mathrm{O}_{5}$ in the urban atmosphere by thermal decomposition/laser-induced fluorescence technique, Atmos. Environ., 39, 6802-6811, 2005.

Mazurenka, M., Orr-Ewing, A. J., Peverall, R., and Ritchie, G. A. D.: Cavity ring-down and cavity enhanced spectroscopy using diode lasers, Annu. Rep. Prog. Chem., Sect C., 101, 100-142, 2005.

Meinen, J., Thieser, J., Platt, U., and Leisner, T.: Using a high finesse optical resonator to provide a long light path for differential optical absorption spectroscopy: CE-DOAS, Atmos. Chem. Phys. Discuss., 8, 10665-10695, 2008, http://www.atmos-chem-phys-discuss.net/8/10665/2008/.

Nakayama, T., Ide, T., Taketani, F., Kawai, M., Takahashi, K., and Matsumi, Y.: Nighttime measurements of ambient $\mathrm{N}_{2} \mathrm{O}_{5}, \mathrm{NO}_{2}$, $\mathrm{NO}$ and $\mathrm{O}_{3}$ in a sub-urban area, Toyokawa, Japan, Atmos. Environ., 42, 1995-2006, 2008.

Orphal, J., Fellows, C. E., and Flaud, P. M.: The visible absorption spectrum of $\mathrm{NO}_{3}$ measured by high-resolution Fourier transform spectroscopy, J. Geophys. Res., 108, 4077, doi:10.1029/2002JD002489, 2003.

Paul, J. B., Lapson, L., and Anderson, J. G.: Ultrasensitive absorption spectroscopy with a high-finesse optical cavity and off-axis alignment, Appl. Opt., 40, 4904-4910, 2001.

Platt, U., Perner, D., Schröder, J., Kessler, C., and Toennissen, A.: The diurnal variation of $\mathrm{NO}_{3}$, J. Geophys. Res., 86, 1196511970, 1981.

Rohrer, F., Bohn, B., Brauers, T., Brning, D., Johnen, F.-J., Wahner, A., and Kleffmann, J.: Characterisation of the photolytic HONOsource in the atmosphere simulation chamber SAPHIR, Atmos. Chem. Phys., 5, 2189-2201, 2005, http://www.atmos-chem-phys.net/5/2189/2005/.
Sander, S. P., Friedl, R. R., Golden, D. M., Kurylo, M. J., Huie, R. E., Orkin, V. L., Moortgat, G. K., Ravishankara, A. R., Kolb, C. E., Molina, M. J., and Finlayson-Pitts, B. J.: Chemical kinetics and photochemical data for use in atmospheric studies: Evaluation Number 15, Jet Propulsion Laboratory, National Aeronautics and Space Administration/Jet Propulsion Laboratory/California Institute of Technology, Pasadena, CA, 2006.

Simpson, W. R.: Continuous wave cavity ring-down spectroscopy applied to in situ detection of dinitrogen pentoxide $\left(\mathrm{N}_{2} \mathrm{O}_{5}\right)$, Rev Sci. Inst., 74, 3442-3452, 2003.

Slusher, D. L., Huey, L. G., Tanner, D. J., Flocke, F. M., and Roberts, J. M.: A thermal dissociation-chemical ionization mass spectrometry (TD-CIMS) technique for the simultaneous measurement of peroxyacyl nitrates and dinitrogen pentoxide, J. Geophys. Res., 109, D19315, doi:10.1029/2004JD004670, 2004.

Venables, D. S., Gherman, T., Orphal, J., Wenger, J. C., and Ruth, A. A.: High sensitivity in situ monitoring of $\mathrm{NO}_{3}$ in an atmospheric simulation chamber using incoherent broadband cavityenhanced absorption spectroscopy, Environ. Sci. Technol., 40, 6758-6763, 2006.

Wayne, R. P., Barnes, I., Biggs, P., Burrows, J. P., Canosa-Mas, C. E., Hjorth, J., Le Bras, G., Moortgat, G. K., Perner, D., Poulet, G., Restelli, G., and Sidebottom, H.: The nitrate radical: Physics, chemistry, and the atmosphere, Atmos. Environ., 25A, 1-206, 1991.

Wood, E. C., Bertram, T. H., Wooldridge, P. J., and Cohen, R. C.: Measurements of $\mathrm{N}_{2} \mathrm{O}_{5}, \mathrm{NO}_{2}$, and $\mathrm{O}_{3}$ east of the San Francisco Bay, Atmos. Chem. Phys., 5, 483-491, 2005, http://www.atmos-chem-phys.net/5/483/2005/.

Yokelson, R. J., Burkholder, J. B., Fox, R. W., Talukdar, R. K., and Ravishankara, A. R.: Temperature-dependence of the $\mathrm{NO}_{3}$ absorption-Spectrum, J. Phys. Chem., 98, 13144-13150, 1994. 